$\begin{array}{ll}\text { Research Square } & \text { Preprints are preliminary reports that have not undergone peer review. } \\ \text { They should not be considered conclusive, used to inform clinical practice, } \\ \text { or referenced by the media as validated information. }\end{array}$

\title{
Zinc Amount in Dental Enamel can be a Potential Factor of Severe Tooth Wear.
}

\author{
Elzbieta Klimuszko \\ Medical University of Białystok \\ Karolina Orywal \\ Medical University of Białystok \\ Barbara Mroczko \\ Medical University of Białystok \\ Teresa Sierpinska ( $\nabla$ teresasierpinska@gmail.com) \\ Medical University of Białystok
}

\author{
Research Article \\ Keywords: enamel, calcium, magnesium, zinc, copper \\ Posted Date: January 23rd, 2021 \\ DOI: https://doi.org/10.21203/rs.3.rs-150134/v1 \\ License: @ (i) This work is licensed under a Creative Commons Attribution 4.0 International License. Read Full License
}




\section{Abstract}

Objective of the study was to assess the potential role of zinc and copper in the process of severe enamel wear.

Methods: Three groups of dental enamel samples were analyzed: 50 from subjects with worn dentition, 20 from healthy volunteers in vivo and 15 healthy teeth cut longitudinally into seven layers in vitro. The amounts of $\mathrm{Ca}, \mathrm{Mg}$ and $\mathrm{Zn}$ in the enamel bioptates were established using atomic absorption spectroscopy with an air/acetylene flame after acid biopsy technique had been applied. The concentration of Cu was established using an electrothermic method with argon gas on the AA spectrometer.

Results : Mean values of calcium (Ca) and magnesium $(\mathrm{Mg})$ did not differ between all the analyzed specimens. The mean value of zinc amount was very high in the samples obtained from worn teeth comparing to the healthy teeth. Statistically significant difference was confirmed between mean value of zinc amount in severe worn dentition and all the layers in vitro and in vivo. Strong positive relationships between magnesium and zinc contents have been shown at some depths. Significant difference was registered between the amount of copper in the severely worn dentitions compared to the superficial layer of the healthy teeth in vitro and in vivo.

Conclusion: It was found that zinc amount was considerably different when comparing worn dentition and healthy teeth. It appears that zinc metabolism may play an important role in enamel formation and may influence the enamel resistance to wear after tooth eruption.

\section{Introduction}

Enamel is the outermost layer of the crown of the tooth, which is highly mineralized [1]. It is one of the most important structures of the tooth, both from a functional and esthetic point of view [2]. The enamel structure is developed during the long-term process of odontogenesis. At the time of eruption the tooth enamel is completely formed and hardened [3]. The enamel chemical composition and structure are likely to be responsible for the enamel resistance to multiple chemical, thermal and biological external agents [4,5]. Calcium and magnesium are the main building minerals of highly organized crystals that are essential for the enamel structure and resistance. Crystal structure ensures optimal layered pattern of hydroxyapatite. Some ions can cause changes in the crystalline structure, morphology and stability of apatite [1]. Magnesium ions play an important role in the regulation of hydroxyapatite crystal growth and condition the physical and chemical stability of crystals. Magnesium can be adsorbed on the crystal's surface or can be built in its hydration layer [6]. Trace elements, in particular zinc and copper, are actively participating in the process of tooth formation and transformations within the enamel matrix, demineralization and remineralization [7]. They take part in many biochemical processes [8]. Those minerals have the ability to form stable complexes with proteins owing to so called zinc fingers, and take part in enzyme activation or inhibition [9]. Zinc plays a significant role in metabolism of multiple factors and proteins, such as kallikrein 4, alkaline phosphatase, Krox 25 and Krox 26 transcription factors [10] , and enamelysin which has the ability to bind zinc and calcium ions [11]. Zink-containing hydroxyapatite solutions can block the effect of acid attack on enamel by adhering to the enamel surface and forming a protective layer in vivo, and significantly reduce the loss of enamel microhardness caused by bleaching and keep the enamel morphology nearly unchanged [12]. Copper ions inhibit the dental plaque formation, acid solubility of enamel and enamel remineralization [13,14]. Its activity consists in the inhibition of bacterial growth and bacterial metabolic enzymes by oxidising thiol groups [15]. However, little is known about the role of copper in enamel formation.

Correctly formed enamel is the most resistant to wear, and alterations in the enamel composition may considerably influence its resistance to the conditions in the oral cavity [16]. There are a lot of theories explaining why the pathological process of tooth wear occurs. Among different theories of pathological tooth wear, the hypothesis, that some unknown processes occurring during enamel formation accelerate tooth wear, appears to be worthy to assess [13, 17-19].

The objective of the study was to assess the potential role of zinc and copper in the process of severe enamel wear.

\section{Material And Methods}

To assess calcium, magnesium, zinc, and copper amounts three groups of dental enamel samples were analyzed: 50 from subjects with worn dentition and 20 from healthy volunteers in vivo and 15 healthy teeth cut longitudinally into seven layers in vitro.

\subsection{Samples}

1. 50 enamel samples were taken from upper central incisors derived from patients with advanced tooth wear (mean value of tooth wear was $27 \pm 0.52$ according to Smith and Knight Index (TWI), mean patients' age $49.5 \pm 9$ years) [20]. To include patients to the study following criteria were applied: visible features of advanced tooth wear on teeth, no dental caries or periodontal disease, no conservative treatment and preventive professional application of fluoride in a dental clinic prior to recruitment to the study,

2. 20 enamel samples were taken from upper central incisors without signs of pathological tooth wear from healthy volunteers aged $48.5 \pm 6$ years,

3. 15 human permanent central upper incisors with completed formation and without any visible pathological changes (donors between 18 and 21 years of age, who expressed their written informed consent for using their extracted teeth for studies) were used in the study. Mechanical damage in the area of alveolar process or changes in periodontium were an indication for tooth extraction. They were prepared for the study in accordance with ISO/TS 11405:2015 [21].

\section{Ethical approval}


The clinical data were conformed to the criteria of The Helsinki Declaration, ICH Guideline for Good Clinical Practice. This protocol was approved by the Local Ethical Committee of the Medical University of Bialystok, Poland, with an approval number of R-I-003/6/2006. Informed consent was obtained from each participant at the beginning of the study prior to confirmation of their eligibility for the study. The participants were able to withdraw from the study at any time and for any reason without prejudice.

\subsection{Study design}

The study was conducted according to the scheme:

1) teeth preparation and acid biopsy in vivo

2) teeth preparation and acid biopsy in vitro

3) biochemical analysis of samples using AAS (atomic absorption spectrometry) method.

\subsubsection{Clinical procedure for tooth wear patients and volunteers}

The acid biopsy technique was applied to assess the $\mathrm{Ca}, \mathrm{Mg}, \mathrm{Zn}$ and $\mathrm{Cu}$ contents in the tooth enamel [22]. The enamel of the labial surface of the maxillary central incisors was cleaned with pumice, rinsed and dried. Four analytical grade filter paper discs were placed in the middle part of the surface prepared. Next, $1 \mu \mathrm{l}$ of $0.1 \mathrm{~mol} / 1$ perchloric acid solution $\left(\mathrm{HClO}_{4}\right)$ was pipetted directly onto the middle of each of these discs. The acid was transferred using a micropipette (Eppendorf Varipipette 4710, Eppendorf-Nethler-Hinz, Germany). The acid was allowed to work on the enamel for $60 \mathrm{~s}$. Immediately after removing the filter paper discs, the biopsy area was rinsed with distilled water and dried. Fluoride gel was applied to the enamel to protect the place of biopsy. The bioptates were transferred to $1.5 \mathrm{ml}$ sterilized, capped tubes (Safe-Lock, Eppendorf, Germany). One well-qualified individual performed all of the biopsies.

\subsubsection{Extracted Teeth preparation}

Longitudinal cuts in the central part of the labial surface of extracted teeth were done using a MICROM HM355S microtome, International GmbH. to obtain enamel layers of $150 \mu \mathrm{m}$. The cutting plane and distance between successive cuts were determined on the basis of the location of and distance between the

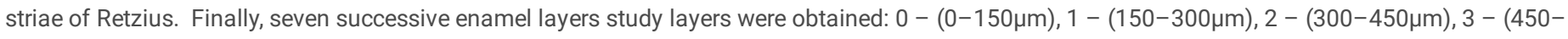
$600 \mu \mathrm{m}), 4-(600-750 \mu \mathrm{m}), 5-(750-900 \mu \mathrm{m}), 6-(900-1050 \mu \mathrm{m})$. The procedure of acid biopsy was utilized on the each enamel layer. Biopsy specimens were marked with letters from $\mathrm{A}$ to $\mathrm{O}$ (designation of the study tooth) and assigned a successive number corresponding to a depth of the study layer.

\subsubsection{Biochemical analysis}

Before biochemical analysis bioptates were mineralized using microwave mineralization (Uni Clever Il, Plazmatronika, Poland). This method was used to completely degrade organic matter and convert it into inorganic substances. The amounts of $\mathrm{Ca}, \mathrm{Mg}$ and $\mathrm{Zn}$ in the enamel bioptates were established using atomic absorption (AA) spectroscopy with an air/acetylene flame (Hitachi Model Z-500, Spectro, Germany) [22]. The concentration of each element was calculated using a calibration curve, and the curve for each element was constructed using the instrument. The concentration of Cu was established using an electrothermic method with argon gas on the AA spectrometer, as calculated from the appropriate calibration curve. The cut-off points for the methods used were: $0.31 \mathrm{mg} / \mathrm{l}$ for $\mathrm{Ca}, 0.017 \mathrm{mg} / \mathrm{l}$ for $\mathrm{Mg}, 0.011 \mathrm{mg} / \mathrm{l}$ for $\mathrm{Zn}$ and $0.42 \mu \mathrm{g} / \mathrm{l}$ for $\mathrm{Cu}$.

Reproducibility and reliability agreement of the methods used were found to be $90 \%$.

\subsection{Statistical analysis}

The statistical description of individual characteristics was done. The study variables were quantitative in nature and arithmetic mean and standard deviation were provided for those variables. The distribution of parameters was similar to linear; therefore, the analysis was carried out using parametric tests. The strength of relationships between the pairs of study parameters was measured using the Pearson's linear correlation coefficient, and its significance was evaluated using the t-test for the correlation coefficient. The results for which the $\mathrm{p}$ value was $<0.05$ were considered to be statistically significant.

The statistical analysis of results obtained was performed using Statistica 10.0., StatSoft PL.

\section{Results}

Mean values and standard deviations (SD) of calcium, magnesium, zinc and copper for worn dentition, healthy teeth in vivo and particular layers of healthy teeth in vitro are presented in the Table 1. It is worthy to note that mean values of calcium (Ca) and magnesium (Mg) did not differ between all the analyzed specimens, and statistical difference was not found between superficial layer of healthy teeth and worn dentition in vivo, and particular layers of enamel in vitro for calcium and magnesium amounts. However, the most interesting finding was revealed for zinc amounts. The mean value of zinc amount was very high in the samples obtained from worn teeth comparing to the healthy teeth. Statistically significant difference was confirmed between mean value of zinc amount in severe worn dentition and all the layers, also superficial one of healthy teeth in vitro ( $00: p<0.001,0: p<0.001,1: p<0.001,2$ : $p<0.001,3: p<0.001,4$ : $p<0.001,5: p<0.001,6: p<0.001)$ and in vivo $(p<0.01)$. 
Table 1

The amounts of calcium (Ca), magnesium $(\mathrm{Mg})$, zinc $(\mathrm{Zn})$ and copper $(\mathrm{Cu})$ in the study groups

\begin{tabular}{|c|c|c|c|c|c|c|c|c|c|c|}
\hline & $\begin{array}{l}\text { Worn teeth } \\
(n=50)\end{array}$ & $\begin{array}{l}\text { Healthy } \\
\text { teeth in vivo } \\
\text { (20) }\end{array}$ & 00 & $\begin{array}{l}0(0-150 \\
\mu \mathrm{m})\end{array}$ & $\begin{array}{l}1(150-300 \\
\mu \mathrm{m})\end{array}$ & $\begin{array}{l}2(300-450 \\
\mu \mathrm{m})\end{array}$ & $\begin{array}{l}3(450-600 \\
\mu \mathrm{m})\end{array}$ & $\begin{array}{l}4(600-750 \\
\mu \mathrm{m})\end{array}$ & $\begin{array}{l}5(750-900 \\
\mu \mathrm{m})\end{array}$ & $\begin{array}{l}6(900- \\
1050 \mu \mathrm{m})\end{array}$ \\
\hline $\begin{array}{l}\mathrm{Ca} \\
{[\mathrm{mg} / \mathrm{l}]}\end{array}$ & $1.88 \pm 1.38$ & $1.85 \pm 1.24$ & $1.42 \pm 0,39$ & $1.86 \pm 1.54$ & $1.59 \pm 1.22$ & $1.89 \pm 1.63$ & $1.96 \pm 0.86$ & $1.56 \pm 0.96$ & $1.47 \pm 1.39$ & $1.45 \pm 1.29$ \\
\hline $\begin{array}{l}\mathrm{Mg} \\
{[\mathrm{mg} / \mathrm{l}]}\end{array}$ & $0.30 \pm 0.14$ & $0.33 \pm 0.15$ & $0.18 \pm 0.08$ & $0.2 \pm 0.07$ & $0.31 \pm 0.19$ & $0.25 \pm 0.15$ & $0.26 \pm 0.16$ & $0.26 \pm 0.09$ & $0.31 \pm 0.13$ & $0.34 \pm 0.13$ \\
\hline $\begin{array}{l}\mathrm{Zn} \\
{[\mathrm{mg} / \mathrm{l}]}\end{array}$ & $0.14 \pm 0.04$ & $0.08 \pm 0.06$ & $0.04 \pm 0.01$ & $0.06 \pm 0.02$ & $0.09 \pm 0.05$ & $0.07 \pm 0.03$ & $0.07 \pm 0.05$ & $0.06 \pm 0.03$ & $0.05 \pm 0.02$ & $0.07 \pm 0.05$ \\
\hline $\begin{array}{l}\mathrm{Cu} \\
{[\mu \mathrm{g} / \mathrm{l}]}\end{array}$ & $22.03 \pm 17.45$ & $36.67 \pm 22.66$ & $10.42 \pm 5.56$ & $17.87 \pm 6.59$ & $16.45 \pm 3.54$ & $16.22 \pm 8.63$ & $20.98 \pm 12.2$ & $17.65 \pm 7.71$ & $17.21 \pm 7.16$ & $14.55 \pm 4.27$ \\
\hline
\end{tabular}

$00,0,1,2,3,4,5,6$ - particular layers of enamel in healthy, extracted teeth.

Relationships between the magnesium and zinc contents in individual enamel layers (in vitro), taking into consideration the Pearson's linear correlation coefficient and the significance level $(p)$ for a particular correlation are presented in figures. Statistically significant $(p<0.05)$ strong positive relationships

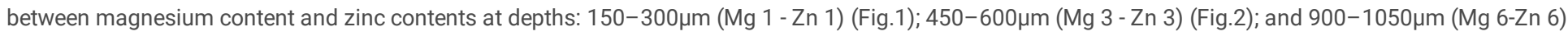
(Fig.3) have been shown.

When analyzing copper amounts, few essential findings were revealed. The only significant difference was registered between the amount of copper in the severely worn dentitions compared to the superficial layer of the healthy teeth in vitro $(p<0.01)$ and in vivo $(p<0.01)$.

\section{Discussion}

It is difficult to judge what is the primary source of advanced tooth wear and if tooth development may play any role in this process. It is also difficult to establish one single etiological factor of advanced enamel wear. The structure and composition of enamel as well as their environment may be regarded as determinants of the dental lesions [23]. Animal studies tried to explain many of the controversies, but the human model may differ from the animal one. Enamel is made up of inorganic and organic parts; therefore, a decision was made to analyze the relationship of calcium and magnesium macro-elements (the main enamel-forming minerals) on zinc and copper micro-elements (related to the enamel formation and changes). Macro- and micro-elements contained in the inorganic part of the tooth should occur at strictly defined concentrations [8], because owing to them multiple metabolic processes are initiated in the dental tissue during the individual development. Disturbed proportions or absence of some elements can affect the content of other minerals and result in a greater tooth vulnerability to dental caries and other pathological agents [8]. When analysing relationships between calcium and zinc in the enamel, the enamel formation period before tooth eruption should be taken into consideration. An enzyme called enamelysin, which is capable of binding $2 \mathrm{Ca}^{2+}$ and 2 $\mathrm{Zn}^{2+}$ ions, is the most active during the secretory stage of enamel formation [11]. The elevated zinc level in some enamel layers is associated with the high activity of enamelysin which inhibits the transformation of amorphous calcium phosphate to hydroxyapatite crystals [24]. Zinc is also an inhibitor of KLK4 of which abnormal activity is associated with abnormal enamel maturation and its reduced calcification. Enamel has normal spatial organization in the absence of KLK 4; however, its mineralization decreases with the increasing depth [25]. A conclusion could be drawn on this basis that the zinc content increases with the decreasing calcium content (lower enamel calcification). The testing performed as part of the study has not confirmed it, which may result from the study teeth contact with the oral cavity environment for many years. According to some authors, the absorption of zinc by enamel may be a part of post-eruptive enamel maturation [26]. There are reports that zinc is capable of modifying the growth of hydroxyapatite crystals, of which the main component is calcium. The mechanism of $\mathrm{Zn}^{2+}$ ion absorption on the hydroxyapatite crystal surface [27] affects the growth inhibition of not only hydroxyapatite crystals, but also their precursors, dicalcium phosphate dihydrate (DCPC) and octacalcium phosphate (OCP) [28]. Studies with synthetic hydroxyapatite showed that zinc can be incorporated into the hydroxyapatite crystal lattice which leads to its increased resistance to acid [1]. During this process, the central calcium atom is replaced by zinc [12]. Therefore, zinc competes with calcium for positions on the apatite crystal surface and can be easily displaced by calcium from hydroxyapatite [29]. Calcium can also reduce zinc adsorption by hydroxyapatite precursors, and this effect is potentially intensified by the increased number of growth centres which are not occupied by zinc [30]. The above reports suggest that the zinc content increases with the decreasing calcium content in hydroxyapatite, because calcium is displaced by zinc. However, this hypothesis has not been confirmed by the conducted study.

Metabolism of magnesium in human enamel is not well studied. As far as it is known magnesium is present in the enamel as magnesium phosphate. It may also influence the activity of alkaline phosphatase and may catalyze the process of properly shaped hydroxyapatite crystal development. Magnesium may also inhibit the transition of calcium phosphate from non-crystallized into crystallized form [31,32]. It has also been reported that magnesium can be easily replaced by zinc in biological systems; therefore, the buffered concentration of zinc is held at least a million-fold below the magnesium content inside the majority of cells [29]. Such relationship may also apply to the tooth enamel in the formation period. In studies on rats it has also been proven that inappropriate diet fed to pregnant mothers affects the zinc and magnesium levels in dental hard tissues in 2-month-old offspring. A decrease in the content of those minerals in dental hard tissues in 2-month-old offspring has also been observed with decreasing zinc and magnesium contents in the mother's diet [33]. Attention should be drawn to the fact that correlations between magnesium and zinc are cyclical in nature in a way (every $150 \mu \mathrm{m}$ ), which can also be associated with the cyclical and phased enamel formation. This process is reflected by the presence of the striae of Retzius in the enamel structure [32]. It has been proven that zinc is essential for the normal enamel formation and its deficiency means a greater tooth vulnerability to dental caries. However, the presence of abnormal enamel areas has been noted in studies on children's teeth after cancer treatment (chemotherapy). In those patients, the enamel showed 
higher magnesium and zinc levels compared to the control group [34]. It can be concluded on this basis that the zinc content increases with the increasing magnesium content, and the enamel resistance to pathological factors is reduced. The results obtained in the study demonstrated two times higher mean value of zinc in the worn dentitions when compared to healthy teeth.

Few reports about interactions between calcium and copper in the tooth enamel have been found. It is believed that the mechanism of copper ion action after the tooth eruption consists in the creation of insoluble copper phosphate layer on the tooth surface. The demineralization is reduced and inhibited by the precipitation of a protective copper phosphate phase through the crystal lattice stabilization on the enamel surface [14]. A conclusion can be drawn on this basis that the enamel calcium content increases with the increasing copper level in the solution surrounding the tooth, as its solubility is reduced. Animal studies suggest that $\mathrm{Cu}$ deficiency is associated with reduced bone strength and deterioration of bone quality leading to osteoporotic lesions [35]. Matrix proteinase 20 cleaves aggrecan, cartilage oligometric matrix protein, type $\mathrm{V}$ collagen, type XVIII collagen, fibronectin and any other proteins [3]. Pro-collagen $\mathrm{N}$ proteinase is engaged it the extracellular metabolism of the enamel matrix. It can be inactivated to $50 \%$ by copper when its amount is in the range of $14-40$ $\mu \mathrm{M}$. Also, glucosyl-transferase is inactivated by copper and gelatinase A and B is inactivated by both zinc and copper [36].

Summarizing, it was found that zinc amount was considerably different when comparing worn dentition and healthy teeth. Even if, it is very speculative but it appears that zinc metabolism during enamel formation and maturation may influence the future enamel resistance to wear. Thus, it is necessary to continue the research to explain the role of zinc in the process of wear.

\section{Declarations}

\section{Author contributions:}

E. K. and T. S. conceived and planned the study.

E. K. and K. O. carried out the study and took the lead in writing the manuscript.

B. M. made statistics and prepared graphs

T. S. contributed to the interpretation of the results and supervised the protocol.

All authors contributed to manuscript revision, red and approved the submitted version.

\section{Conflicts of Interest:}

The author(s) declare no competing interests.

\section{References}

1. Fatima, T., Rahim, H. A., Lin, Z. B., Qamar, C. W. \& Zinc, Z. A precious trace element for oral health care? J Pak Med Assoc. 66, 1019-1023 (2016).

2. Sabel, N. Enamel of primary teeth-morphological and chemical aspects. Swed Dent J. 120 (Suppl.1), 1-77 (2012).

3. Bartlett, J. D., Skobe, Z., Nanci, A. \& Smith, C. E. Matrix metalloproteinase 20 promotes a smooth enamel surface, a strong dentino-enamel junction, and a decussating enamel rod pattern. Eur J Oral Sci. 119 (Suppl 1), 199-205 (2011).

4. Sa, Y. et al. Compositional, structural and mechanical comparisons of normal enamel and hypomaturation enamel. Acta Biomater. 10, 5169-5177 (2014).

5. Yahyazadehfar, M., Bajaj, D. \& Arola, D. D. Hidden contributions of the enamel rods on the fracture resistance of human teeth. Acta Biomater. 9, 48064814 (2013).

6. Weatherel, J. Composition of dental enamel. Brit Med Bull. 31, 115-119 (1975).

7. Bartlett, D. W., Anggiansah, A., Owen, W., Evans, D. F. \& Smith, B. G. N. Dental erosion: a presenting feature of gastro-oesophegeal reflux disease. Eur J Gastoenterol Hepatol. 6, 895-900 (1994).

8. Bialek, M. \& Zyska, A. The biomedical role of zinc in the functioning of the human organism. Pol J Public Health. 124, 160-163 (2014).

9. Gapys, B., Raszeja-Specht, A. \& Bielarczyk, H. Role of zinc in physiological and pathological processes of the body. Diagn Lab. 50, 45-52 (2014).

10. Lee, S. K. et al. Molecular cloning, chromosomal mapping, and characteristic expression in tooth organ of rat and mouse Krox - 25. Genomics. 83, 243253 (2004).

11. Andreini, C., Banci, L., Bertini, I., Luchinat, C. \& Rosato, A. Bioinformatic comparison of structures and homology-models of matrix metalloproteinases. $J$ Proteome Res. 3, 21-31 (2004).

12. Li, Y., Shi, X. \& Li, W. Zinc-containing hydroxyapatite enhances cold-light-activated tooth bleaching treatment in vitro.Biomed Res Int. ID6261248 (2017)

13. Sierpinska, T., Orywal, K., Kuc, J., Golebiewska, M. \& Szmitkowski, M. Enamel mineral content in patients with severe tooth wear. Int J Prosth. 26, 423-428 (2013).

14. Brookes, S. J., Shore, R. C., Robinson, C., Wood, S. R. \& Kirkham, J. Cooper ions inhibit the demineralization of human enamel. Arch Oral Biol. 48, 25-30 (2003).

15. Abdullach, A. Z., Strafford, S. M., Brookes, S. J. \& Duggal, M. S. The effect of cooper on demineralization of dental enamel. J Dent Res. 85, 1011-1015 (2006) 
16. Bartlett, J. D. et al. A developmental comparison of matrix metalloproteinase-20 and amelogenin null mouse enamel. Eur J Oral Sci. 114 (Suppl 1), 18-23 (2006).

17. Loomans, B., Optam, N., Attin, T., Bartlett, D. \& Edelhoff, D. Severe Tooth Wear: European Consensus Statemen on Managment Guidelines. J Adhesive Dent. 19, 111-119 (2017).

18. Wetselaar, P. \& Lobbezoo, F. The tooth wear evaluation system: a modular clinical guideline for the diagnosis and management planning of worn dentition. J Oral Rehab. 43, 69-80 (2016).

19. Sovik, J. B., Vieira, A. R., Tveit, A. B. \& Mulic, A. Enamel formation genes associated with dental erosive wear. Caries Res. 49, 236-242 (2015).

20. Smith, B. \& Knight, J. An Index for measuring the wear of teeth. Br Dent J. 156, 435-438 (1984).

21. Technical specification ISO/TS 11405:2015(en): Dentistry-Testing of adhesion to tooth structure.

22. Milosevic, A. \& Dawson, L. J. Salivary factors in vomiting bulimics with and without pathological tooth wear. Caries Res. 30, 361-366 (1996).

23. Grippo, J. O., Simring, M. \& Schreiner, S. Attrition, abrasion, corrosion and abfraction revisited. A new perspective on tooth surface lesions. JADA. 135, 1109-1118 (2004).

24. Prajapati, S., Tao, J., Ruan, Q., De Yoreo, J. J. \& Moradian-Oldak, J. Matrix metalloproteinase-20 mediates dental enamel biomineralization by preventing protein occlusion inside apatite crystals. Biomaterials. 75, 260-270 (2016).

25. Yamakoshi, Y., Tanabe, T., Fukae, M. \& Shimizu, M. Porcine amelogenins. Calcif Tissue Int. 54, 69-75 (1994).

26. Fang, M. M., Lei, K. Y. \& Kilgore, L. T. Effects of zinc deficiency on dental caries in rats. J Nutr. 110, 1032-1036 (1980).

27. Stötzel, C., Müller, F. A., Reinert, F., Niederdraenk, F. \& Barralet, J. E. Gbureck, U. Ion adsorption behaviour of hydroxyapatite with different crystallinities. Colloids Surf Biointerfaces. 74, 91-95 (2009).

28. Mneimne, M. et al. Physical chemical effects of zinc on in vitro enamel demineralization. J Dent. 42, 1096 - 104(2014)

29. Rahman, M. T., Hossain, A., Pin, C. H. \& Yahya, N. A. Zinc and metallothionein in the development and progression of dental caries. Biol Trace Elem Res. 5, 12011-12018 (2018).

30. Davey, H. P., Embery, G. \& Cummins, C. Interaction of zinc with a synthetic calcium phosphate mineral. Caries Res. 31, 434-440 (1997).

31. Aoba, T. Recent observations on enamel crystal formation during mammalian amelogenesis. Anatomical Record. 245, 208-218 (1996).

32. Smith, C. E. Cellular and chemical events during enamel formation. Crit Rev Oral Biol Med. 9, 128-161 (1998).

33. Nikolayeva, O.\& Pysmenna, O. The influence of unbalanced nutrition of pregnat rats on the content of biogenic elements in the enamel and blood serum of their offspring. Georgian Med News. 278, 163-168 (2018).

34. Krasuska-Slawinska, E., Dembowska-Baginska, B., Brozyna, A., Kowalczyk, O. \& Czarnowska, D. E., Sowinska, A. Changes in the chemical composition of mineralised teeth in children after antineoplastic treatment. Contempor Oncol. 22, 37-41 (2018).

35. Medeiros, D. M. et al. Femurs from rats fed diets deficient in copper or iron have decreased mechanical strength and altered mineral composition. $J$ Trace Elem Exp Med. 10, 197-203 (1997).

36. Souza, A. P., Gerlach, R. F. \& Line, S. R. P. Inhibition of human gingival gelatinases (MMP-2 and 9) by metal salts. Dent Mater. 16, 103-108 (2000).

\section{Figures}

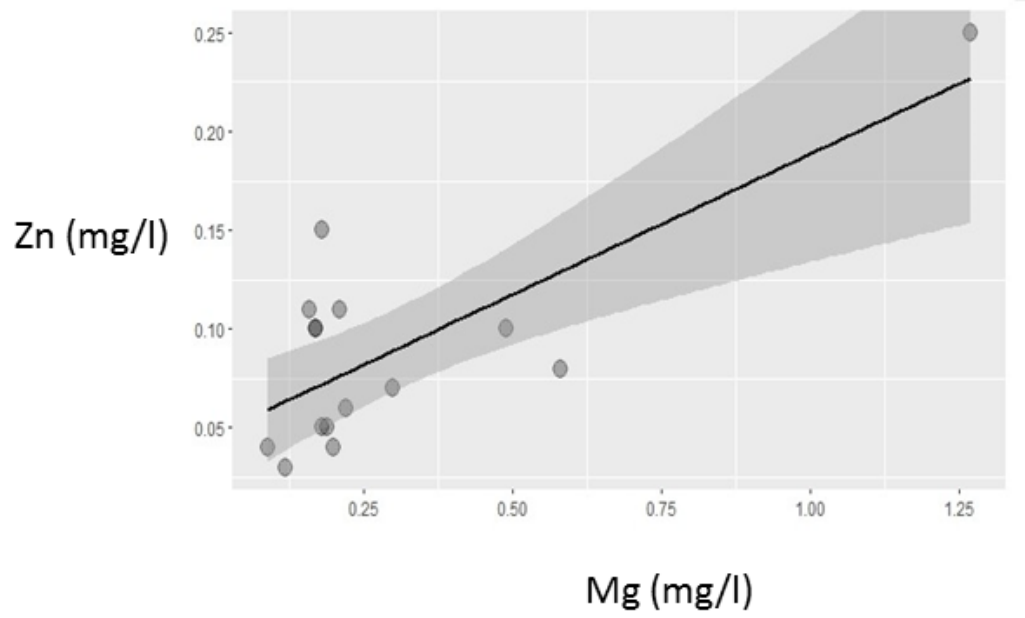

\section{Figure 1}

Relationships between the magnesium and zinc contents at depth: $150-300 \mu \mathrm{m}(r=0.762, p<0.05)$ 


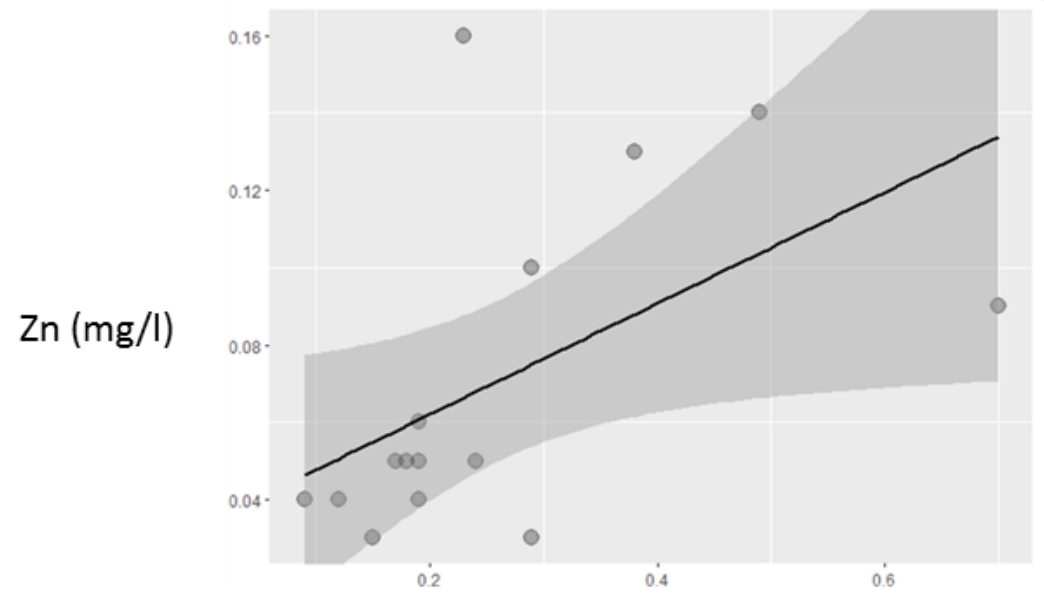

\section{$\mathrm{Mg}(\mathrm{mg} / \mathrm{l})$}

\section{Figure 2}

Relationships between the magnesium and zinc contents at depth: $450-600 \mu \mathrm{m}(r=0.535, p<0.05)$

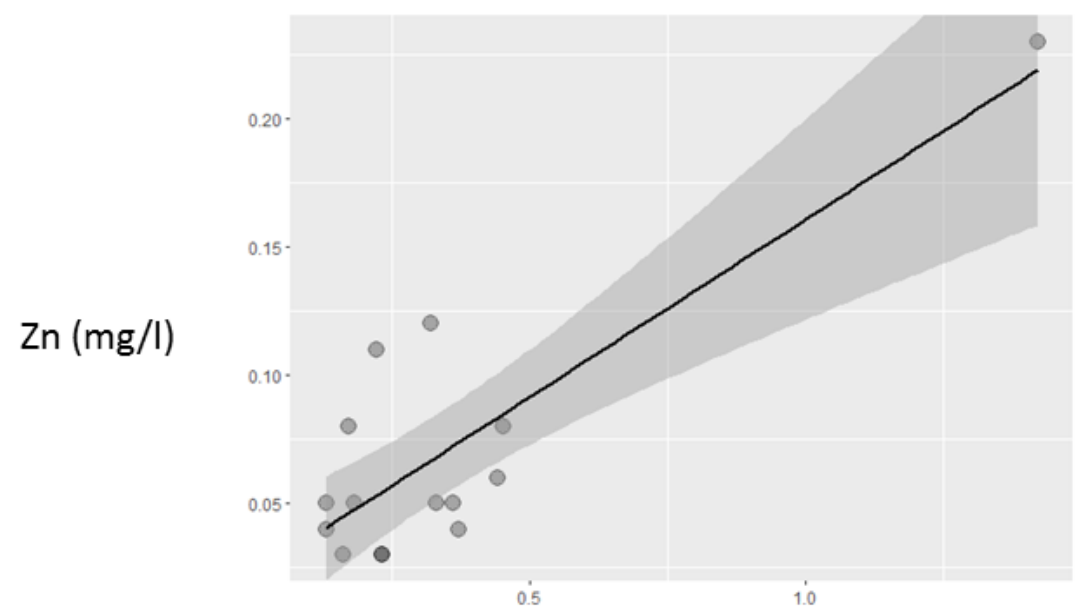

\section{$\mathrm{Mg}(\mathrm{mg} / \mathrm{l})$}

Figure 3

Relationships between the magnesium and zinc contents at depth: $900-1050 \mu \mathrm{m}(r=0.837, p<0.05)$ 